CREATE-ing capacity to take developmental crime prevention to scale

CREATE-ing capacity to take developmental crime prevention to scale: A community-based approach within a national framework

\author{
Ross Homel, PhD \\ Kate Freiberg, PhD \\ Sara Branch, PhD \\ Griffith Criminology Institute
}

Published as:

Homel, R., Freiberg, K. \& Branch, S. (2015). CREATE-ing capacity to take developmental crime prevention to scale: A community-based approach within a national framework. Australian and New Zealand Journal of Criminology 48(3): 367-385 


\title{
CREATE-ing capacity to take developmental crime prevention to scale: A community-based approach within a national framework
}

\begin{abstract}
Developmental crime prevention is founded on the long-term outcomes and economic efficiency of about 50 promising or model programs for fostering healthy child and youth development and for preventing crime. However, few if any of these programs have been successfully implemented on a large scale, a problem that is the focus of Type 2 (T2) Translation Research within prevention science. This paper describes one approach to building capacity for population-level community-based developmental prevention using the CREATE model that we developed as an outcome of the Pathways to Prevention Project that operated in a disadvantaged region of Brisbane between 2002 and 2011. CREATE is an acronym: Collaborative; Relationships-driven; Early in the pathway; Accountable; Training-focused; Evidence-driven. CREATE is being used to develop, in T2 Translation terms, a prevention support system (PSS) for the Communities for Children (CfC) program, a prevention delivery system that is operated by the Department of Social Services in 52 communities across Australia. The aim is to build the capacity for schools and community agencies to transcend system silos; foster ethical practices and respectful relationships; and deliver goal-directed, quantitatively evaluated, evidence-based resources that address the needs of families with complex needs, promote child wellbeing, and prevent antisocial and criminal behaviours. The PSS combines web-based interactive electronic resources for schools and community agencies serving children in CfC communities with systems and processes established by project personnel called Collective Impact Facilitators who build the skills and knowledge of community coalitions to use the electronic resources and implement CREATE effectively. This capacity building exercise is being evaluated through a comprehensive array of pre- and post-measures of coalition functioning. The PSS integrates with national prevention infrastructure developed by DSS, including a Data Exchange System, an Expert Panel, and an Information Exchange.
\end{abstract}


CREATE-ing capacity to take developmental crime prevention to scale

The first core challenge [of Type 2 Translation Research] is to build infrastructures and the capacity for broad translation of evidence-based preventive interventions into community practices through prevention delivery systems. ... The second core challenge is to clarify and conduct the range of necessary scientific advances required for investigation of sustained, high-quality implementation of [evidence-based interventions] at scale. (Spoth et al., 2013; p. 322)

This paper is about one approach to realising the promise of developmental crime prevention on a large scale. That is, it is about investing in capacity to build on the success of a growing number of relatively small-scale innovations that have demonstrated convincingly that it is possible, in an economically efficient way, to create conditions early in life or in childhood that foster healthy developmental pathways and reduce adolescent and adult rates of involvement in antisocial behaviour and crime (Manning, Homel \& Smith, 2010; Piquero et al., 2009).

Only in the past decade or so have some of the conceptual tools essential for the journey from 'success-in-miniature' to population-level impact been developed (Schorr, 1998). This process of 'scaling up' is referred to in the prevention science literature as Type 2 Translation, in contrast to Type 1 Translation that applies the results of basic research to the development and testing of new prevention initiatives (Spoth et al., 2013). Not only are the basic concepts relatively new, but the empirical evidence for successful Type 2 (T2) Translation strategies is currently very limited, not only for crime but for health and other social objectives (Fagan \& Eisenberg, 2012; Farrington \& Welsh, 2007; Homel \& McGee, 2012).

This paper describes our approach to building capacity for population-level communitybased prevention using the CREATE model that we developed as an outcome of the Pathways to Prevention Project that operated in a disadvantaged region of Brisbane between 2002 and 2011 (Branch, Homel \& Freiberg, 2012; Homel et al., 1999; Homel, Elias \& Hay, 2001; Homel, 2005). CREATE is an acronym: Collaborative; Relationshipsdriven; Early in the pathway; Accountable; Training-focused; Evidence-driven. These 
CREATE-ing capacity to take developmental crime prevention to scale

key terms, which are summarised in Figure 1 and explained further throughout this paper, are an attempt to encapsulate the main principles underpinning a model of preventative action that - in the context in which we are applying it - empowers schools and community agencies to transcend system silos; foster ethical practices and respectful relationships; and deliver goal-directed, quantitatively evaluated, evidencebased resources that promote child wellbeing in disadvantaged communities and, in particular, help deflect children from antisocial and criminal behaviours.

Our specific concerns in this paper are therefore crime and disadvantaged communities, the institutions that operate in these localities, and the children and families living in them. However it is important to keep in mind that the CREATE principles are in themselves completely general, and could underpin prevention activities in nondisadvantaged communities. Indeed the model could be the foundation for prevention initiatives that are not place-based at all, or are directed at problems other than youth crime (such as healthy aging), or are focused on whole populations. The approach is, in other words, universal and flexible with no specific problem focus.

As part of our explanation of the CREATE model, we outline how we are contributing to the nascent Australian research on T2 Translation in partnership with a range of government and non-government agencies, using the Australian government's Communities for Children Program as a framework (Edwards et al., 2014) ${ }^{1}$. We place this research in the context of the growing emphasis by the Department of Social Services (which developed and administers Communities for Children) on evidence-based practice, and the widespread enthusiasm amongst policy people, practitioners, and social entrepreneurs for collaborative approaches that achieve collective impact. Kania and Kramer (2011), the originators of the term, define collective impact as:

... long-term commitments by a group of important actors from different sectors to a common agenda for solving a specific social problem. Their actions are supported by a shared measurement system, mutually reinforcing activities, and ongoing communications, and are staffed by an independent backbone organization. (p.39)

As will become apparent, the concept of collective impact and the principles of the CREATE model (and of Communities That Care and related prevention initiatives) have 
CREATE-ing capacity to take developmental crime prevention to scale

a great deal in common, and for this reason we have been happy to adopt the collective impact framework as a way of communicating our ideas. However our judgment is that the collective impact movement, at least in its current stage of development, is weakened by widespread ignorance of prevention science and by a corresponding lack of attention to carefully researched evidence on what works.

INSERT FIGURE 1 ABOUT HERE

\section{Why CREATE?}

CREATE has been strongly shaped by the Pathways Project. Key considerations have been:

1. Our intuition that much of what community agencies do in socially disadvantaged communities is quite effective despite being mostly unevaluated (Homel et al., 2006);

2. Our observation that strong interpersonal relationships and creative forms of outreach that build trust with the community, and particularly with so-called 'hard to reach families,' are fundamental for effective practice;

3. Our observation that evidence-based programs figure very little in the plans and practices of busy practitioners; and

4. Our frustration with the governance arrangements that underpinned the Pathways Project, especially the divide between schools, community agencies and families (Branch, Homel \& Freiberg, 2013).

Beyond what we have learned from the Pathways Project, experience internationally over the last two decades with the implementation of evidence-based innovations (Fixsen et al., 2009) and with crime prevention partnerships have helped shape our thinking. Particularly important have been the lessons about effective governance arrangements for prevention partnerships (Crawford, 1998; Homel \& Homel, 2012), one of the most central being the need for strategic vision with roles and responsibilities clearly defined. In the Pathways work there was no adequate mechanism for hammering out specific goals that were shared by schools, community workers and 
CREATE-ing capacity to take developmental crime prevention to scale

researchers, resulting in confusion around roles and relationships. The interrelatedness of goals, roles, procedures and relationships, with goals at the apex and relationships at the base of a conceptual triangle of good organisation, was identified many years ago in the management literature and applies with considerable force to community partnerships (Plovnick, Fry \& Rubin 1975).

As we have foreshadowed, the array of new T2 Translation concepts and frameworks in the prevention science literature has also been a formative influence on our thinking, especially the Interactive Systems Framework for Dissemination and Implementation developed by Abraham Wandersman and his colleagues (2008). An important feature of the ISF is the clear distinction between:

1. The Prevention Delivery System that implements innovations in the world of practice;

2. The Prevention Support System which provides training, technical assistance or other support to users in the field; and

3. The Prevention Synthesis and Translation System which distils information about innovations and translates it into user-friendly formats.

These systems are characterised by their activities, not by specific individuals or organizations, and each system depends on the others in complex ways. For example, the active involvement of practitioners from the delivery system in the support system will help ensure the development of useful products, and a thorough understanding by researchers of the social, cultural and political contexts within which preventive innovations will be delivered might do much to bridge the much lamented gulf between science and service - or in the language of the ISF, the gap between the synthesis and translation system and the delivery system. As important examples of prevention delivery systems, Communities That Care (CTC) and Communities for Children (CfC) are described below.

\section{Communities That Care}

CTC is a community-based prevention system that was developed in the 1980s by the Social Development Research Group at the University of Washington in the United 
CREATE-ing capacity to take developmental crime prevention to scale

States. It has been implemented widely in the United States, including through the Center for Substance Abuse Prevention in the US Government, and also operates in many countries in Europe, Australia, and elsewhere (Toumberou et al. in press). CTC involves the formation of collaborative partnerships among community stakeholders to spearhead adoption and support of evidence-based interventions that have been shown to reduce risk and enhance protective factors for adolescent behavior problems. CTC is now accumulating impressive evidence for population-level impacts in Pennsylvania and elsewhere in the United States (Feinberg et al., 2010; Hawkins et al., 2009), and has been a very important influence on our thinking. At least some of the success of CTC may be attributed to the availability of 'intermediate organisations' like the EvidenceBased Prevention and Intervention Support Center within the Prevention Research Centre at Pennsylvania State University. The EPISCenter, in its own words, "supports the dissemination, quality implementation, sustainability, and impact assessment of a menu of proven-effective prevention and intervention programs," thereby constituting a critical part of a prevention support system for Pennsylvania and beyond ${ }^{2}$. We characterize the EPISCenter as an intermediate organization because it acts as an intermediary between researchers and practitioners in a large number of creative ways (Bumbarger \& Campbell, 2012; Rhoades, Bumbarger \& Moore, 2012). A wide range of similar support systems have contributed to the success of CTC elsewhere in the United States (Fagan et al., 2012).

Despite its achievements, the impact of CTC on crime and substance abuse has not specifically been demonstrated in highly disadvantaged or urban communities, most successes being recorded for rural and suburban areas (Brown et al., 2010). Since socially disadvantaged areas produce more young offenders and are less socially cohesive than more privileged areas, this is an important issue for youth crime prevention (Wickes, Homel \& Zahnow, in press). In addition the CTC model perhaps has some structural weaknesses as a national prevention delivery system, at least for Europe and countries like Australia, Canada and New Zealand where the welfare state has survived in more vigorous forms than in the United States. The persistence of a stronger safety net in these countries suggests that government needs to occupy a more central place in prevention planning. Both these considerations led us to develop the 
CREATE-ing capacity to take developmental crime prevention to scale

CREATE model applied to child wellbeing as a complementary approach to CTC that explicitly addresses these apparent weaknesses.

\section{Communities for Children}

The use of community coalitions is a central element of how we are currently applying the CREATE model. This approach is shared with CTC (Oesterle et al. 2010) and other community-based prevention innovations in the United States, including the drug prevention program PROSPER (Spoth et al., 2011) and the emerging Evidence2Success model (Fagan \& Eisenberg, 2012; Ripper \& Ortiz, 2012). The starting point in our current work is the service provider partnerships in 10 of the 52 Communities for Children communities, all of which are (as core selection criteria) located in disadvantaged urban and regional areas of Australia with a high incidence of children not meeting the milestones of health and development expected for their age, as measured by the Australian Early Development Census (Centre for Community Child Health, 2007). The fundamental goal of CfC is to improve the wellbeing of children aged 0 to 12 years in the selected communities. Government funding is provided to a nongovernment organisation in each area (the facilitating partner) which establishes and maintains a partnership of community agencies that design and deliver services in response to community needs. However, until recently there has been no regulatory mechanism for ensuring that truly evidence-based activities are implemented, no systems for monitoring and improving implementation processes, no requirement to quantify patterns of participation by families and children in the services offered by a partnership, and no measurement of outcomes. A recent quasi-experimental evaluation of CfC impact at the community level (Edwards et al., 2014) found that "although there were a number of positive (and a few negative) effects of the $\mathrm{CfC}$ initiative, most were not durable and faded out by the time children started school" (p. xiii).

CREATE aims to overcome some of the limitations in Communities for Children but has much wider application. Critically, a key sustainability strategy is to build capacity for evidence-based developmental prevention within the framework of a national program (CfC) that has not only survived several changes of government since it began in 2004 but has grown in size and sophistication. 
CREATE-ing capacity to take developmental crime prevention to scale

\section{Unpacking CREATE}

Behind much developmental prevention thinking are the concepts of equifinality and multifinality (Cicchetti \& Rogosch, 1996). Equifinality refers to the fact that the same end state (such as participation in youth crime) may be reached by multiple pathways, such as a lack of capacity for self-regulation combined with inadequate parental supervision in the early years, or an antisocial peer group and disrupted school attachment in early high school. Multifinality refers to the fact that individuals may begin on the same major pathway but because of personal attributes, subsequent choices, or life events exhibit very different patterns of adaptation or maladaptation. Thus children raised in similar 'toxic environments' characterised by harsh and erratic discipline, family violence, and poverty, may become well functioning adults, chronic offenders, homeless, or mentally ill. Multifinality means that successful early prevention initiatives tend to have multiple benefits over the life course (Manning et al., 2010), while equifinality means that successful initiatives are frequently multi-systemic, targeting a number of aspects of the social ecology such as family, school, and peer group. The reality of multifinality, combined with a growing emphasis by academics and practitioners on positive youth development and strength-based approaches in preference simply to the prevention of negative outcomes (Lerner \& Overton, 2008), means that it is often theoretically desirable and strategically sensible to frame prevention initiatives as promoting 'positive development' or 'child and youth wellbeing,' rather than as crime prevention or drug prevention or some other kind of prevention. For these reasons the CREATE principles in Figure 1 are framed by the overarching goal of Better lives for children in disadvantaged communities.

Underpinning all aspects of CREATE (and hence in bold at the bottom of Figure 1) is relational developmental systems theory (DST), closely aligned in the work of Richard Lerner and his colleagues with the study of positive youth development (Lerner, 2002; Lerner \& Castellino, 2002; Lerner \& Overton, 2008). The central emphasis within this perspective is on the dynamic relations among structures from multiple levels of organisation; that is, on the time-varying processes linking individuals with all aspects of their contexts. "Levels of organization" are conceptualized extremely broadly, ranging 
CREATE-ing capacity to take developmental crime prevention to scale

from the biological and inner-psychological through the proximal social relational (especially within the context of the family) through local community levels to the socio-cultural and social structural. Within this post-positivist, inter-disciplinary perspective, human agency and relative plasticity across the life course are central concepts, and family processes, social institutions and societal access routes that open up opportunities to take new directions are fundamental to the preventive enterprise (France and Homel, 2006).

DST has many implications for practical prevention work in communities. One implication is the need to think broadly about the major influences on growing children, both inside and outside the community, and to identify those influences - particularly the specific contexts, local groups and organisations - that are potentially amenable to inclusion in preventive initiatives. Since relations between individuals, contexts and levels of organization are fundamental building blocks of the developmental system, community action must be focused as much on connections or transactions between individuals and between organisations as on the capabilities of individuals or the quality of developmental contexts. Strengthening relationships between people and the connections between organisations is clearly one important goal, but from a systems perspective community building cannot stop there: even more important is how the various elements of the system operate as a whole for the benefit of children. As Branch and colleagues (2012, p. 294) put it: “... agencies and institutions ideally need to operate within a framework of collaborative practice, characterised by a blurring of the boundaries between organisations and by harmonious, mutually supportive practices in families, schools, community agencies, and other key settings." The strengthening and harmonisation of learning environments within families and local schools was a central goal of the Pathways to Prevention Project, chiefly through the provision of comprehensive and integrated forms of family support and child activities, in partnership with primary schools.

Collaboration and Relationships provide the first two letters of the CREATE acronym, for reasons that should now be apparent in the light of the systems perspective. All six CREATE principles could be discussed in much more detail than is possible in this paper, 
CREATE-ing capacity to take developmental crime prevention to scale

so in what follows we concentrate on Collaborative practice since it allows us to draw into the discussion aspects of Relationships, Accountability and Training as well as the undergirding practices of good governance and empowerment (of parents, children, and the 'child-serving' workforce). Building on the foundational thinking in the 1999 Pathways to Prevention report (Developmental Crime Prevention Consortium, 1999) we take the principle of Early in the Pathway largely as read, although we recognise that issues such as the timing of interventions (e.g., should early always mean early in life?: Hayes, 2007) and the balance of universal and targeted programs are critically important in shaping delivery and support systems. Evidence-driven is a bedrock principle in CREATE that is reserved for extended discussion after we examine collaborative practice.

\section{Collaborative practice}

Although it is a general model, CREATE was conceived primarily with a place-based approach in mind because it is within a locality that a shared understanding of complex problems can be more easily arrived at and used to guide collaborative practice (Fry et al., 2014). We also envisaged that community partnerships in some form would be both the vehicle through which local priorities and strategies are decided as well as a primary delivery system at the local level. However a key problem, if the overall goal is to strengthen the developmental system, is that many partnerships are dominated by community agencies and government organisations rather by the enduring developmental institutions that most influence children, especially schools, preschools, churches, and - most critically - families ${ }^{3}$. Indeed parents or carers, as one of the primary target groups for the activities devised by community partnerships, are frequently absent from the table altogether, even if they are sometimes included in community consultations of various forms. Children and young people typically have even less of a voice, although understanding what it means in practice to treat children as social actors and then to act on what we learn from them is a challenging enterprise (France \& Homel, 2006; James, 2007).

Getting schools into community partnerships is equally challenging, even though many of the most difficult problems schools face, such as serious antisocial behaviour or 
CREATE-ing capacity to take developmental crime prevention to scale

learning difficulties, have their origins largely outside the school gates and require external resources and the cooperation of families to address effectively. Since many of the standard risk factors for youth crime, such as impulsivity (Farrington \& Welsh, 2007), also predict poor academic performance and conflict with school (often because of disruptive and antisocial behaviours), bridging the yawning chasm between families and schools in disadvantaged communities can provide a very effective platform for both community-based crime prevention and for promoting learning outcomes (Freiberg, Homel \& Branch, 2010; Feinberg et al., 2010). However it is a daunting prospect for principals and teachers to initiate engagement so that parents and community members both create and contribute to initiatives that support (say) reading development at home and in partnership with the school (Dempster et al., 2012; Johnson \& Jervis-Tracey, 2011).

Our experience in the Pathways to Prevention Project is that when offered external resources principals were keen to cooperate and to refer children to the family support team, but were generally unwilling or felt unable to take responsibility for shared goal setting and for the development of joint initiatives tailored to their needs. In short, schools were reluctant to take the next step along the continuum from cooperation with community workers and coordination of school and Pathways activities through timetabling, to full collaboration, an experience duplicated in many sectors where horizontal service integration has been attempted (Keast et al., 2007). As Bruder (2005, p.31) has put it, in the history of service integration "one is struck by its nobility of intent, its tenacity of purpose, and its ineffectiveness in implementation." Our experience is that collaborative practice across the school-community sector divide is especially problematic because teachers have a very strong occupational culture and schools are traditionally independent organisations with their own clearly focused goals and well-established organisational structures.

Collaboration, as distinct from cooperation and coordination, requires a high degree of trust among members which allows a commitment to a common mission and to system change (Keast et al., 2007). The historic failure of attempts at collaboration or service integration, despite the rhetoric and despite more than one hundred years of effort, 
CREATE-ing capacity to take developmental crime prevention to scale

underpins the growing consensus amongst researchers, social entrepreneurs and practitioners that collaboration is not possible without an external impetus and in the absence of specialised resources that are independent of the organisations delivering services. In the collective impact approach popularised by Kania and Kramer (2011), the solution to this problem is to introduce a separate organisation - the backbone organisation - with staff that have the skills that makes it possible for participating organisations to adopt a common agenda; share data and adopt common measures; engage in mutually reinforcing activities; and communicate consistently and openly. Backbone organisations can take many forms, ranging from existing or new non-profits to a senior level steering committee (Hanleybrown, Kania and Kramer, 2012).

The functional equivalent of a backbone organisation within the CREATE framework, and within the $\mathrm{CfC}$ project, is a prevention support system that provides human and electronic resources that make it possible for $\mathrm{CfC}$ partnerships to move from coordination to collaboration; to agree on a small number of measurable goals for children in the light of needs revealed through data on the wellbeing of children in the community; to develop community action plans underpinned by a theory of change; to share agency data on family participation in activities and relevant outcome measures; and to select, implement with fidelity, and evaluate evidence-based programs. Every one of these steps is challenging for community coalitions, although many have independently made significant progress on some aspects, such as the assessment of the needs of children in the light of available data ${ }^{4}$.

In specific terms, the CfC project is developing:

1) An interactive web-based set of resources, consisting of such elements as:

a) Training tools for $\mathrm{CfC}$ teachers and community workers; motivational videos and infographics; and games for child-parent learning and for measurement of outcomes;

b) Evaluation tools for measuring community coalition function; child \& family outcomes; resources for doing economic analyses;

c) A data sharing management system. 
CREATE-ing capacity to take developmental crime prevention to scale

2) Systems and processes established by community workers that we call 'Collective Impact Facilitators' who work with community coalitions to build the skills and knowledge:

a) To implement the CREATE community prevention model using the electronic resources;

b) To achieve the core conditions of collective impact.

These project resources are being integrated with other resources developed by the federal government, including: (a) a sophisticated and user-friendly national Data Exchange System that will facilitate the development of community state-of-the-child reports; inter-agency data sharing and reporting at local levels and beyond; measurement of outcomes; and program evaluations ${ }^{5}$; (b) an Expert Panel of individuals and organisations that will provide technical support to individual agencies and community coalitions ${ }^{6}$; and (c) the Child Family Community Australia (CFCA) Information Exchange, a web-based source of quality, evidence-informed publications, research and resources related to children, families and communities (Robinson \& Knight, 2012).

No matter how sophisticated the technical supports, the success of community coalitions depends on the establishment of good governance systems that regulate the way power is exercised and account rendered, and ensure that energy is directed at better outcomes for children. The principles of effective governance for healthy coalitions have been invented and reinvented in many contexts, including public health (Butterfloss, 2007) and the collective impact movement ${ }^{7}$. There is a remarkable degree of similarity in the adduced principles, with Homel \& Homel's (2012) analysis of what constitutes good governance for crime prevention partnerships as useful as any:

1. Legitimacy and voice: power is acquired and exercised in a way that is perceived as legitimate, and all affected by decisions are heard and can have an influence. This means, amongst other things, that everyone who needs to be is at the table.

2. Strategic vision: the exercise of power results in a clear sense of direction that serves as a guide to action. This means that roles and responsibilities are clearly defined. 
CREATE-ing capacity to take developmental crime prevention to scale

3. Performance: Organisations and processes are responsive to the interests of participants and stakeholders. Critically, performance is monitored and reported within an agreed framework, while being sensitive to the contexts in which parties work.

4. Accountability: There is transparency and openness in the work of the coalition, including measurement and reporting of outcomes.

5. Fairness: There is conformity with the rule of law (e.g., privacy laws) and the principle of equity.

An important area of contemporary activity within prevention science is the development of a rigorous evidence-base for these and similar governance principles, focusing on the measurement of the dimensions of a healthy coalition and the critical characteristics for achieving impact. For example, in their analysis of community-level mediators in the CTC community trial in the United States, Brown and colleagues (2014) have shown that the effects of the CTC intervention on youth problem behaviours by the end of eighth grade were mediated fully by community adoption of a science-based approach to prevention. Of course many other features of coalitions, such as strength of leadership and strong internal and external relationships, feed into support for high quality evidence-based programs (Brown et al., 2010). The CREATE capacity building exercise is being evaluated through a similarly comprehensive array of pre- and post-measures of coalition functioning (especially orientation to evidence), but regrettably, despite their emphasis on data and measurement, there appears to be limited appreciation by collective impact proponents of the importance of evidencebased programs.

\section{Rethinking evidence-based developmental crime prevention}

The foundations for developmental crime prevention rest on the impressive long-term outcomes and economic efficiency of a repository of more than 50 promising or model programs for fostering healthy youth development and for preventing or reducing crime, violence and substance abuse. One of the most widely used sources for information on evidence-based prevention is the aptly named Blueprints for Healthy Youth Development, developed by Del Elliott and colleagues at the University of 
CREATE-ing capacity to take developmental crime prevention to scale

Colorado (Mihalic \& Elliott, 2014). These programs span the range from universal interventions that are provided for the general population or for all members of a specified collectivity like a local community; selective interventions directed at groups judged to be at increased risk; and indicated interventions directed at individuals already manifesting a problem such as disruptive behaviour (Mrazek \& Haggerty, 1994). They also vary greatly according to problem focus (e.g., antisocial behaviour, alcohol abuse), target age range (from preschool or before birth to university students), and the context for intervention (home, community, school, workplace). What unites the programs presented in the Blueprints web site and other registries of evidence-based interventions is their careful design and focus on key risk and protective factors (Farrington, 2002); evaluations using high-quality randomised or quasi-experimental designs; and effects that are sustained for at least 12 months after the program intervention ends.

Establishing high standards for model or promising evidence-based programs is important, since as Mihalic and Eliott (2014, p. 2) observe, "lower standard comes with a greater risk of failure when programs are subsequently implemented on a wider scale." The downside of this, however, is that high standards might make it harder to actually move to scale, because suitably trained staff are not available, or high quality costs too much, or is in conflict with prevailing professional norms, or for any number of other reasons documented in the implementation science literature (Homel \& Homel, 2012). Experience with preschool education provides an instructive example of the gap between flagship programs and general practice.

The HighScope Perry Preschool program is perhaps the most influential evidence-based developmental crime prevention initiative ever conducted, even though it began life more than 50 years ago as a short-term evaluation of the effects of an innovative preschool curriculum on the intellectual and language performance of 58 three- and four-year old African-American children, compared with 65 controls, growing up in poverty in Ypsilanti, Michigan. The project was well designed, well implemented, and rigorously evaluated, but the main reason it has been so influential is because the authors continued to follow-up the program sample and the randomised controls, 
CREATE-ing capacity to take developmental crime prevention to scale

expanding the range of outcome measures over a 40-year period to include school achievement, commitment to schooling, childhood antisocial behaviour, high school graduation, adult employment and earnings, and youth and adult crime and incarceration. The outcomes at all follow-up points across all these domains favoured the program group, with the study presenting "strong evidence of a lifetime effect of the High Scope Perry Preschool program in preventing total arrests and arrests for violent, property, and drug crimes and subsequent prison or jail sentences" (Schweinhart, 2013, p. 397).

The HighScope early childhood educational model, which is "an open framework of educational ideas and practices based on the natural development of young children" (Schweinhart, 2013, p. 394), was the foundation for both the daily classroom activities and weekly home visits for 90 minutes to each mother and child. Both these program strands, by encouraging children to make choices, solve problems, and engage in activities that promoted both cognitive development and (especially) social adjustment and capacity for self-regulation (Heckman et al., 2013), contributed to the long-term reductions in crime and improvements in social and economic wellbeing. The point is that the intervention made it possible for a small group of infants to flourish in a manner that resembled, at least in some degree, the 'natural' development of children raised in more privileged circumstances. Unfortunately the critical ingredients in this innovative program - highly qualified teachers, a valid child development curriculum, extensive engagement of parents, and regular assessment of program implementation and child development - have not generally been reproduced in the large-scale federal Head Start program in the United States, which typically has weak short-term effects with small likelihood of long-term benefits (Puma et al., 2012). The good news, however, is that many local preschool programs in the US are highly effective, at least in the short term (Schweinhart, 2013). These findings, concerning the large-scale and the local, are important beyond the realm of early childhood education, and have informed the development of the CREATE model.

Expanding the definition of evidence 
CREATE-ing capacity to take developmental crime prevention to scale

Shonkoff and Fisher (2013) have distilled many of the challenges facing developmental criminologists engaged in T2 Translation, even though their focus is early childhood policy and practice with crime prevention only one of many benefits envisaged. One element of their argument is that flagship programs like the Perry Preschool Program should be viewed primarily through a historical lens and their seminal contribution appreciated as proof of concept rather than as evidence for the value of current investments. They point out that for all their benefits, these flagship programs generally produce modest effect sizes and fall far short of constituting optimum early prevention models. In the Perry Preschool Study, for example, a third of the intervention group had at least one arrest for a violent offence, reinforcing the need for "more effective strategies to produce larger effects" (p. 1637). They acknowledge the great value of quality improvement and system building (including enhanced data management practices and better coordinated services), but are sceptical that these will be sufficient to produce the breakthrough impacts for children growing up under the burdens of poverty, parents with limited education, and social exclusion.

One of their key proposals relates to the need for an expanded definition of evidence and for innovation in T1 research: translating the wealth of new findings from child development research and prevention science into new types of preventive innovations. They observe that in a policy environment that increasingly emphasises evidence-based programs, there is little funding or encouragement for the development and testing of new ideas. They are particularly concerned that new findings from neuroscience be translated into "ecologically valid intervention strategies that promote the practice of specific behavioural skills that are known (or hypothesized) to be manifestations of the underlying neural systems of interest in real-world settings" (p. 1639). This could lead, for example, to innovative new ways of effecting improvements in the neural mechanisms of self-regulation, a dimension of great interest to criminologists.

While strongly endorsing this proposal for the expansion of the evidence base, we are of the view that the development of new preventive initiatives should not be restricted to those based on neuroscience - very important as these are - but should encompass all forms of sound research. To take a 'frontier issue' in community crime prevention as an 
CREATE-ing capacity to take developmental crime prevention to scale

example, in seminal research Sampson and his colleagues have demonstrated that rates of community violence and violent victimisation result from the differential ability of neighbourhoods to realise the common values of residents and maintain effective social controls, capacities that they refer to as collective efficacy. Even in communities characterised by weak ties, when residents trust each other and are willing to work together to solve local problems, violence is lower (Sampson et al., 1997). This begs the obvious question: do prevention delivery systems like CTC, which explicitly build or strengthen local coalitions and empower them to address local problems using evidence-based practices, improve levels of community collective efficacy, particularly levels of social cohesion and trust? There is intriguing evidence that they might. Brown and colleagues (2014), for example, found that CTC strengthened community norms against adolescent drug use, which suggests that related community constructs such as social cohesion and trust might well be amenable to being influenced by the coalition approach. The basic problem is that evidence-based strategies to strengthen informal social controls are in their infancy (Wickes, Homel \& Zahnow, in press), partly because prevention science has concentrated too much on individual and family risk factors for violence and not enough on community-level social processes (Haegerich, Oman, Vesely, Aspy \& Tolma, 2014). Research to bridge this gap could yield important new innovations that could strengthen both community and developmental crime prevention and aid the development of integrated approaches.

A further way that the evidence base can be expanded is prompted by Schweinhart's (2013) finding that many local preschool programs were very effective, even if the national Headstart program wasn't. A comprehensive repository of successful local preschool initiatives, including a careful analysis of their critical operating characteristics, would make an important contribution to the Prevention Synthesis and Translation System envisaged by Wandersman and colleagues, and would complement Blueprints and similar registries of evidence-based programs developed and tested by researchers. This proposal exactly parallels what Mark Lipsey has developed through extensive meta-analyses of the evaluations of hundreds of 'no name' treatment programs for young offenders that are usually restricted to one jurisdiction or locality. His Standardized Program Evaluation Protocol is "a data-driven rating scheme built 
CREATE-ing capacity to take developmental crime prevention to scale

around the intervention characteristics found to be most strongly related to recidivism reductions in the meta-analysis ..." (Lipsey, 2014, p. 9), greatly expands the evidencebase of what works for young offenders, and the processes underlying success (type of program, amount of service, quality of delivery, and risk level of participants).

In summary, we propose that 'evidence-driven' for developmental crime prevention consist of three kinds of preventive initiatives:

1. The model or promising programs in registries of evidence-based programs, such as Blueprints;

2. Promising innovations developed and rigorously evaluated through a T1 process, preferably in partnership with practitioners and with data collected 'in the field' rather than in a clinic or laboratory;

3. Activities routinely offered in communities across Australia and elsewhere, such as facilitated playgroups, family support, or after-school programs, provided there are a sufficient number of experimental or well-designed quasiexperimental evaluations that demonstrate impact on the risk factors for antisocial behaviour and other child outcomes, and that also provide guidance on the processes highlighted by Lipsey (2014), such as amount of service that is optimal.

Model programs should of course be given priority if they fit the community need, with established practices that are well evaluated the second preference. However, opportunities to add new knowledge about effective prevention through strong researcher-practitioner partnerships should also be encouraged wherever possible. The forms of evidence that actually underpin activities in CfC communities will be subjected to detailed analysis and evaluation as they develop within the new DSS framework ${ }^{1}$.

\section{Riding the wave: why the time is right to 'think big'}

This paper has described the CREATE model of community prevention as one approach to T2 translation: taking evidence-based practice to scale. CREATE emerged from the struggle in the Pathways to Prevention Project to instantiate the principles of developmental crime prevention in partnership with schools and a national community 
CREATE-ing capacity to take developmental crime prevention to scale

agency in one socially disadvantaged region of one Australian city, but we argue that its principles are applicable to all forms of developmental prevention on a much larger scale, including initiatives that are not place-based. In the spirit of prevention science, and with the goal of sustainability, we are subjecting CREATE to comprehensive evaluation, beginning with a capacity building phase through Communities for Children, a national place-based program for children and families in 52 disadvantaged areas. While CfC arguably falls short of constituting a truly national prevention delivery system (since it is restricted to selected disadvantaged communities which do not, for example, include remote Aboriginal communities), it is an ideal vehicle for testing some T2 translation strategies on a much larger scale than would be possible in a universitybased initiative.

All this is taking place in a climate of renewed interest in the use of data and evidencebased programs to improve the lives of children and young people through prevention and early intervention (Andrews, 2014), supported by major developments in the enabling infrastructure at a national level (including the Data Exchange System, the Expert Panel, and the CFCA Information Exchange). This movement has gained considerable extra impetus because of the unsustainable growth in the numbers of children 'known' to the child protection system and the widespread acknowledgment of the ineffectual nature of tertiary responses.

The history of social reform movements based on rigorous science, including the areas of climate change and harm caused by alcohol, demonstrates that when evidence conflicts with powerful entrenched interests, the entrenched interests nearly always win. However developmental prevention has no natural enemies (except perhaps when adolescent alcohol abuse or foetal alcohol spectrum disorder are the targets), since it involves doing what a very large majority of citizens, business people and politicians want to do in any case: strengthen families and communities and foster better lives for disadvantaged children. Now is the time for prevention-oriented criminologists to grasp the opportunities provided by the convergence of the recent breakthroughs in prevention science with the urgent policy priorities that have stimulated the development of promising new national infrastructure for developmental prevention. 
CREATE-ing capacity to take developmental crime prevention to scale

\section{Acknowledgments}

The CfC project is funded through an Australian Research Council Linkage grant LP130100142 (2014-2016). Pathways to Prevention has been funded through ARC grants since 1999, most recently through DP0984675 (2009-13). We are grateful to the two reviewers of this paper for extremely helpful comments, and also to Jon Bright, Alan Hayes, Peter Homel, Dorothy Scott, and Robyn Seth-Purdie for their generous commitment of time, careful readings, and very helpful critiques.

\section{Endnotes}

1. The nature, operations and impact of the CfC project are described in detail in separate papers in preparation.

2. http://www.episcenter.psu.edu/

3. We base this assertion on a preliminary survey of coalition memberships in $10 \mathrm{CfC}$ communities, but also more broadly on observations of communities throughout Australia.

4. For example, State of the Children and Young Persons' Report 2014: Ipswich and West Moreton (Child, Youth and Family Alliance, Ipswich and West Moreton); The State of Launceston's Children 2014 (Anglicare Tasmania).

5. The DSS Data Exchange Framework: A new approach for streamlined programme performance reporting. Canberra: Department of Social Services, July 2014.

6. https://www3.aifs.gov.au/cfca/families-and-children-activity-expert-panel

7. The Tamarack Institute, Resources at a Glance: Collaborative Governance: http://tamarackcommunity.ca/ 
CREATE-ing capacity to take developmental crime prevention to scale

\section{References}

Andrews, K. (2014, July 21). Address to the Annual Coalition of Organisations Committed to the Safety and Wellbeing of Australia's Children. Melbourne.

Branch, S., Homel, R. \& Freiberg, K. (2012). Making the developmental system work better for children: Lessons learned from the Circles of Care Programme. Child and Family Social Work 18, 294-304. DOI: 10.1111/j.1365-2206.2012.00845.x

Brown, E.C., Hawkins, J.D., Rhew, I.C., Shapiro, V.B., Abbott, R.D., Oesterle, S., Arthur, M.W., Briney, J.S. \& Catalano, R.F. (2014). Prevention system mediation of Communities That Care effects on youth outcomes. Prevention Science, 15, 623-632

Brown, L.D., Feinberg, M.E. \& Greenberg, M.T. (2010). Determinants of community coalition ability to support evidence-based programs. Prevention Science, 11(3): 287-97.

Bumbarger, B.K. \& Campbell, E.M. (2012). A state-university partnership for translational research and the dissemination of evidence-based prevention and intervention. Administration and Policy in Mental Health and Mental Health Services Research 39, 268-277.

Butterfoss, F.D. (2007). Coalitions and Partnerships in Community Health. USA: JosseyBass.

Centre for Community Child Health (2007). Australian Early Development Index: Building better communities for children, final evaluation report. Melbourne: Royal Children's Hospital.

Cicchetti, D. \& Rogosch, F.A. (1996). Equifinality and multifinality in developmental psychopathology. Development and Psychopathology, 8, 597-600.

Crawford, A. (1998). Crime prevention and community safety: Politics, policies and practices. Harlow, Essex, UK: Addison Wesley Longman.

Dempster, N., Konza, D., Robson, G., Gaffney, M. Lock, G. \& McKennariey, K. (2012). Principals as Literacy Leaders: Confident, Credible and Connected. Kingston, ACT: Australian Primary Principals Association.

Developmental Crime Prevention Consortium (1999). Pathways to prevention: Developmental and early intervention approaches to crime in Australia (Full Report, Summary and Appendices). Canberra: Australian Government Publishing Service.

Edwards, B., Mullan, K., Katz, I., \& Higgins, D. J. (2014). The Stronger Families in Australia (SFIA) Study: Phase 2. Melbourne: Australian Institute of Family Studies. 
CREATE-ing capacity to take developmental crime prevention to scale

Fagan, A. \& Eisenberg, N. (2012). Latest developments in the prevention of crime and anti-social behaviour: An American perspective. Journal of Children's Services, 7(1), 6472.

Fagan, A.A., Hanson, K., Briney, J.S. \& Hawkins, J.D. (2012). Sustaining the utilization and high quality implementation of tested and effective prevention programs using the Communities That Care Prevention System. American Journal of Community Psychology $49,365-377$

Farrington, D. P. (2002). Developmental criminology and risk-focused prevention. In M. Maguire, R. Morgan \& R. Reiner (Eds.), The Oxford handbook of criminology (3rd ed., pp. 657-701). Oxford: Oxford University Press.

Farrington, D.P. \& Welsh, B.C. (2007). Saving children from a life of crime: early risk factors and effective interventions. Oxford: Oxford University Press

Feinberg, M.E., Jones, D., Greenberg, M.T., Osgood, D.W. \& Bontempo, D. (2010). Effects of the communities that care model in Pennsylvania on change in adolescent risk and problem behaviors. Prevention Science 11:163-171

Fixsen, D. L., Blase, K.A., Naoom, S.F. \& Wallace, F. (2009). Core implementation components. Research on Social Work Practice 16: 531-540.

France, A. \& Homel, R. (2006). Societal access routes and developmental pathways: Putting social structure and young people's voice into the analysis of pathways into and out of crime. Australian and New Zealand Journal of Criminology, 39, 295-309.

Freiberg, K., Homel, R. \& Branch, S. (2010). Circles of Care: The struggle to strengthen the developmental system through the Pathways to Prevention project. Family Matters, 84, 28-34.

Fry, R., Keyes, M., Laidlaw, B., \& West, S. (2014). The state of play in Australian placebased activity for children. Parkville, Victoria: Murdoch Children's Research Institute and The Royal Children's Hospital Centre for Community Child Health.

Haegerich, T.M, Oman, R.F., Vesely, S.K., Aspy, C.B. \& Tolma, E.L. (2014). The predictive influence of family and neighbourhood assets on fighting and weapon carrying from mid- to late-adolescence. Prevention Science, 15, 473-484

Hanleybrown, F., Kania, J. \& Kramer, M. (2012). Channeling change: making collective impact work. Stanford Social Innovation Review (January), 1-9

Hayes, A. (2007). Why early in life is not enough: timing and sustainability in prevention and early intervention. In Alan France \& Ross Homel (Eds.), Pathways and crime prevention: Theory, policy and practice (pp. 202-225). Cullompton, UK: Willan. 
CREATE-ing capacity to take developmental crime prevention to scale

Hawkins, J.D.; Oesterle, S; Brown, E.C.; Arthur, M.W.; Abbott, R.D.; Fagan, A.A. \& Catalano, R.F. (2009). Results of a Type 2 Translational Research Trial to Prevent Adolescent Drug Use and Delinquency: A Test of Communities That Care. Archives of Pediatric Adolescent Medicine, 163(9): 789-798

Heckman, J., Pinto, R. \& Savelyev, P. (2013). Understanding the Mechanisms Through Which an Influential Early Childhood Program Boosted Adult Outcomes. American Economic Review, 103 (6), 2052-86.

Homel, R., Elias, G. \& Hay, I. (2001). Developmental prevention in disadvantaged communities. In Eckersley, R., Dixon, J. \& Douglas, R. (Eds), The Social origins of health and well-being: From the planetary to the molecular (pp. 269-279), Melbourne: Cambridge University Press.

Homel, R. (2005). Developmental crime prevention. In Nick Tilley (Ed.), Handbook of crime prevention and community safety (pp. 71-106). Cullumpton, Devon, UK: Willan Publishing

Homel, R., Cashmore, J., Gilmore, L., Goodnow, J., Hayes, I., Lawrence, J., Leech, M., Najman, J., O'Connor, I., Vinson, T. \& Western, J. (1999). Pathways to prevention: Developmental and early intervention approaches to crime in Australia (Full Report and Appendices) (400 pages). Canberra: Australian Government Publishing Service.

Homel, R., Freiberg, K., Lamb, C., Leech, M., Hampshire, A., Hay, I., Elias, G., Carr, A., Manning, M., Teague, R. \& Batchelor, S. (2006). The Pathways to Prevention Project: The First Five Years, 1999-2004. Sydney: Griffith University \& Mission Australia

Homel, R. \& Homel, P. (2012). Implementing crime prevention: Good governance and a science of implementation. In Brandon Welsh and David Farrington (Eds.), The Oxford Handbook of Crime Prevention (pp. 423-445). Oxford: Oxford University Press

Homel, R. \& McGee, T. (2012). Community approaches to crime and violence prevention: Building prevention capacity. Chapter 20 in Rolf Loeber \& Brandon Welsh (Eds.), The future of criminology (pp. 172-177). New York: Oxford University Press

James, A. (2007). Giving voice to children's voices: practices and problems, pitfalls and potentials. American Anthropologist ,109(2), 261-272

Johnson, G. \& Jervis-Tracey, P. (2011). Re-imagining terms of engagement in leadership for learning for disadvantaged communities and families: An (im)modest proposal. In Tony Townsend \& John MacBeath (Eds.), International handbook of leadership for learning (pp. 1591-1616). Dordrecht: Springer 
CREATE-ing capacity to take developmental crime prevention to scale

Kania, J. \& Kramer, M. (2011). Collective impact. Stanford Social Innovation Review (Winter), 36-41.

Keast, R., Brown, K. \& Mandell, M. (2007). Getting the right mix: unpacking integration meanings and strategies. International Public Management Journal, 10(1), 9-33

Lerner, R.M. (2002) Concepts and theories of human development. L. Erlbaum Associates, Mahwah, N.J.

Lerner, R. M. \& Castellino, D.R. (2002). Contemporary developmental theory and adolescence: Developmental systems and applied developmental science." Journal of Adolescent Health, 31: 122-135.

Lerner, R.M. \& Overton, W.F. (2008). Exemplifying the integrations of the relational developmental system synthesizing theory, research, and application to promote positive development and social justice. Journal of Adolescent Research, 23, 245-255.

Lipsey, M.W. (2014). Interventions for juvenile offenders: A serendipitous journey. Criminology \& Public Policy, 13, 1-14.

Manning, M, Homel, R \& Smith, C. (2010). A meta-analysis of the effects of early developmental prevention programs in at-risk populations on non-health outcomes in adolescence. Children and Youth Services Review, 32, 506-519.

Mihalic, S. F., \& Elliott, D. S. (2014). Evidence-based programs registry: Blueprints for Healthy Youth Development. Evaluation and Program Planning, http://dx.doi.org/10.1016/j.evalprogplan.2014.08.004

Mrazek, P.J. \& Haggerty, R.J. (1994). Institute of Medicine (IOM), Reducing risks for mental disorders: Frontiers for preventive intervention research. Washington D.C.: National Academy Press.

Oesterle, S., Hawkins, J.D., Fagan, A.A., Abbott, R.D., \& Catalano, R.F. (2010). Testing the universality of the effects of the Communities That Care prevention system for preventing adolescent drug use and delinquency. Prevention Science, 11, 411-423.

Piquero, A.R., Farrington, D.P., Welsh, B.C., Tremblay, R. \& Jennings, W.G. (2009). Effects of early family/parent training programs on antisocial behaviour and delinquency. Journal of Experimental Criminology, 5, 83-120.

Plovnick, M., Fry, R. and Rubin, I. (1975). New developments in OD [Organisational Development] technology: Programmed team development. Training and Development Journal, 29(4), 19-25. 
CREATE-ing capacity to take developmental crime prevention to scale

Puma, M., Bell, S., Cook, R., Heid, C., Broene, P., Jenkins, F., Mashburn, A. \& Downer, J. (2012). Third Grade Follow-Up to the Head Start Impact Study: Final Report. OPRE Report 2012-45. Washington, DC: Administration for Children \& Families. US Department of Health and Human Services. http://www.acf.hhs.gov/

Rhoades, B.L., Bumarger, B.K. \& Moore, J.E. (2012). The role of a state-level prevention support system in promoting high-quality implementation and sustainability of evidence-based programs. American Journal of Community Psychology, 50:386-401

Ripper, J. \& Ortiz, A. (2012). Building on what works: Improving children's futures. Better: Evidence-based Education, 4(2), 18-19.

Robinson, E. \& Knight, K. (2012). The Child Family Community Australia (CFCA) Information Exchange. Family Matters, 90, 110-112.

Sampson, R.J., Raudenbush, S.W. \& Earls, F. (1997). Neighborhoods and violent crime: A multilevel study of collective efficacy. Science 277, 918-924.

Shonkoff, J.P. \& Fisher, P.A. (2013). Rethinking evidence-based practice and twogeneration programs to create the future of early childhood policy. Development and Psychopathology, 25, 1635-1653

Schorr, L. (1998). Common purpose: Strengthening families and neighborhoods to rebuild America. New York: Anchor House.

Schweinhart, L.J. (2013). Long-term follow-up of a preschool experiment. Journal of Experimental Criminology, 9, 389-409

Spoth, R., Redmond, C., Clair, S., Shin, C., Greenberg, M., \& Feinberg, M. (2011).

Preventing substance misuse through community-university partnerships: Randomized controlled trial outcomes $4 \frac{1}{2}$ years past baseline. American Journal of Preventive Medicine, 40(4): 440-447

Spoth, R., Rohrbach, L.A., Greenberg, M., Leaf, P., Brown, C.H., Fagan, A., Catalano, R.F., Pentz, M.A., Sloboda, Z., Hawkins, J.D. \& Society for Prevention Research Type 2 Translational Task Force Members and Contributing Authors (2013). Addressing core challenges for the next generation of type 2 translation research and systems: The Translation Science to Population Impact (TSci Impact) Framework. Prevention Science, 14, 319-351.

Toumbourou, J.W., Leung, R., Homel, R., Freiberg, K., Satyen, L., and Hemphill, S.A. (in press). Violence prevention and early intervention: what works? In Andrew Day \& Ephrem Fernandez (Eds.), Preventing violence in Australia: Policy, Practice and Solutions. Sydney: Federation Press 
CREATE-ing capacity to take developmental crime prevention to scale

Wandersman, A., Duffy, J., Flaspohler, P., Noonan, R., Lubell, K., Stillman, L., Blachman, M., Dunville, R. \& Saul, J. (2008). Bridging the gap between prevention research and practice: The Interactive Systems Framework for Dissemination and Implementation. American Journal of Community Psychology, 41, 171-181.

Wickes, R., Homel, R. \& Zahnow, R. (in press). Safety in the suburbs: Social disadvantage, community mobilization, and the prevention of violence. In J. Stubbs \& S. Tomsen (Eds), Australian Violence. Sydney: Federation Press 
Figure 1. The CREATE model for community prevention and the promotion of child and youth wellbeing



